\title{
A tribute to Alan M. Gewirtz
}

W. mourn the untimely passing of Alan Gewirtz, a member of the JCI Editorial Board, who died on November 17, 2010, at the age of 61 .

Alan received his undergraduate degree from Colgate University, where, in keeping with a lifelong interest in the world around him, he majored in marine biology. After graduating from SUNY Buffalo Medical College and completing a medical residency at The Mount Sinai Hospital (New York, New York, USA), he went to Yale University for clinical training in hematology and oncology. While at Yale, he worked with Ron Hoffman, Ed Cadman, and Ed Benz to make seminal contributions to the field of megakaryocyte developmental biology. Later, as an inde-
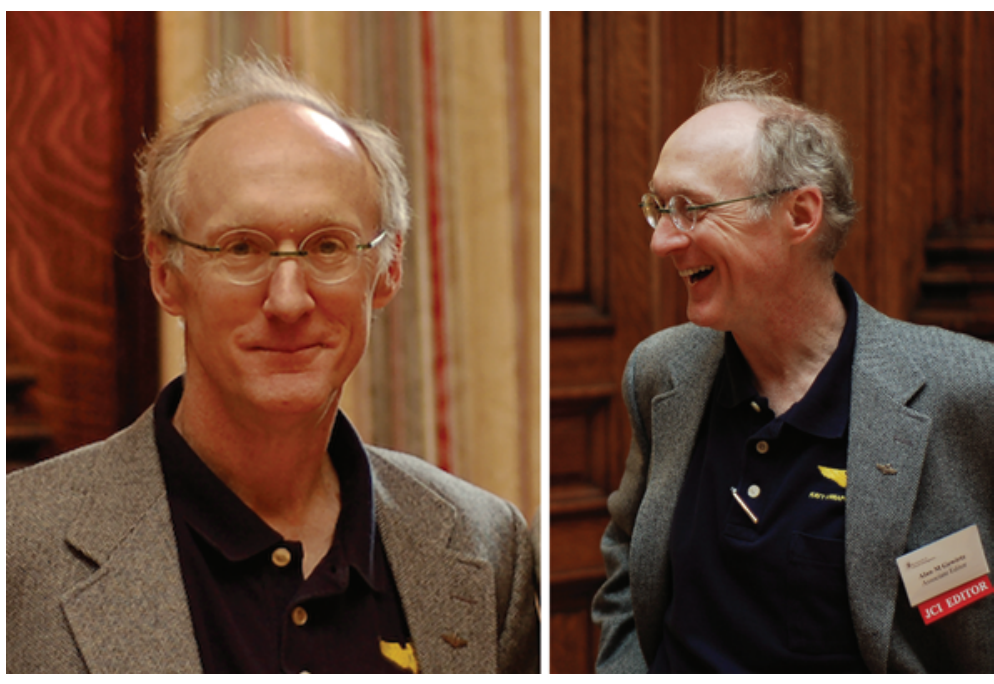

social engagements (at least with either of us!) when he was attending, because he invariably was at the hospital until far past normal dinner hours.

Feisty, loyal, gentle, combative, impassioned, gracious, spirited ... these are all adjectives that readily described Alan. His

minute. After staying up most of the night before the due date, with Alan sleeping on the floor under his desk for a few hours, they had to personally deliver the grants to the Foundation offices. Jim recalls, "After the all-nighter, Alan took one look at me with my sleep-deprived, bloodshot eyes, [and] said there was no way he was going to get in a car with me behind the wheel. Then he said, 'Hoxie, we're taking the plane."”

Alan was a founding member of the Penn JCI Editorial Board. Of the 19 Associate Editors currently on our masthead, only eight served in that capacity for our first issue (March 2007), Alan among them. He was a force in our weekly meetings. He usually held strong opinions, but was always willing to be persuaded by the facts. If he thought the ideas in a manuscript had merit, he

was not an imposing physical presence - he probably never weighed more than 150 pounds - but it is hard to imagine Alan ever backing down when challenged, and we each recall a beet red-faced angry man when he encountered incompetence or rudeness, especially if directed at friends or family. We are all, of course, studies in contrasts, and Alan was simultaneously the gentlest of men. A lover of animals, he frequently snuck his wirehaired dachshund, Sparky, into work by hiding him in a small satchel; Sparky even attended a JCI Editorial Board meeting once.

Alan was a devoted pilot, and was actually funded by NASA to study hematopoiesis in outer space. He shared ownership in a small plane with Meenhard Herlyn of The Wistar Institute and flew as often as he could, whether it was to Study Section, to visit his children at college, or just to get out on a beautiful day. In 1999, Alan and a colleague at Penn, Jim Hoxie, were each nominated to apply for the first Doris Duke Translational Researcher Awards. The time period for the application was brief, and Alan and Jim left it to the last fought passionately for the paper. He was a strong author advocate - he wanted us to publish good science and to publish it quickly, rather than ask the authors to spend months doing "clean-up" experiments that were unnecessary. He also never forgot what the $\mathrm{C}$ in JCI stands for. More than any other Penn board member, past or present, Alan would ask whether the paper, the model, and the experiments were relevant to human disease. If the work could be validated with human samples, he would insist on the authors doing it. Alan never forgot that the mission of biomedical research is to improve human health.

We thank Alan's many friends and colleagues who shared their feelings about him with us - the joy that he brought into their lives, and ours, is palpable. He will be sorely missed.

\section{Laurence A. Turka Editor in Chief}

\section{Stephen G. Emerson} Senior Editor 